\title{
De grutas e estátuas: um corp'a'screver a imagem
}

\author{
Mayara Ribeiro Guimarães ${ }^{1}$
}

\begin{abstract}
RESUMO: Avaliação dos projetos estético-literários clariciano e llansoliano a partir da aprendizagem por meio do e com o outro em narrativa que propõe a ruptura com os modelos de escrita convencionados, regentes do pensamento ocidental, enquanto tema, e da linguagem, enquanto forma, culminando em uma literatura cuja tarefa primordial do escritor é a reflexão sobre a própria escrita, em diálogo com a pintura e a música.

ABSTRACT: Evaluation of the aesthetic and literary projects developed by Maria Gabriela Llansol and Clarice Lispector, concerning what is learned by and with the other in a narrative that seeks a rupture with the conventional models of literature that rule western thinking and culture, as theme, and language, as form, ending up in a literature whose main task is the reflection over the act of writing in itself, in dialogue with painting and music.
\end{abstract}

PALAVRAS-CHAVE: Literatura Comparada; Poética; Imagem.

KEYWORDS: Comparative Literature; Poetics; Imagery.

Para João Barrento, em agradecimento.

"Não há literatura"

(Llansol, Um falcão no punho)

Iniciar por uma das provocações possivelmente mais enfáticas e diretas feita por Maria Gabriela Llansol, em Um falcão no punho (1985), talvez seja uma boa maneira de convocar o leitor para um diálogo com seus textos. Seguindo a trilha deixada pela autora ao afirmar que "não há literatura", estupefato, resta ao leitor perguntar-se em seguida: Que há então? Pedro Mexia, crítico português contemporâneo aponta que Llansol "não escreve ficções, ensaios ou poemas" ${ }^{\prime \prime}$, mas textos que não se constituem como livros no sentido tradicional dado pela historiografia literária tradicional, por não formarem um todo

${ }^{1}$ Doutoranda UFRJ. 
completo. Se não há o todo completo há, no entanto, um fazer poético preocupado com o processo de formação da escrita, que busca não a definição de uma forma, mas a potência de uma força - a do contínuo fazer poético - em movimento inacabado porque vivo. Não é surpresa, portanto, encontrar no depoimento da autora a declaração de que o que escreve "é uma só narrativa, que vou partindo, aos pedaços" (LLANSOL, p. 67, apud BRANCO, 2000, p. 21). Não há o todo completo porque há o encontro com o diverso. “A língua é uma impostura", repete o refrão que marca o tom de Um beijo dado mais tarde (1990) e de uma literatura que percorrerá sempre o caminho do confronto com a tradição, de maneira a atingir a linguagem em sua construção rígida, até encontrar uma língua sem impostura, uma língua em processo de permanente formação e reformulação.

Nesse ponto, convidamos para o diálogo uma outra beguina, cuja escrita tampouco se encaixa em classificações de qualquer ordem: Clarice Lispector. Se, para Llansol, seus textos não permitem uma classificação que os determine como ficções porque sua matéria textual por excelência não deseja ficcionalizar um real exterior à voz do autor - “uma coisa é ou não é” (LISPECTOR, 1978, p. 13) - para Clarice, o que importa, da mesma forma, é o é da coisa, a parte "intangível do real" (idem). "Que mal tem eu me afastar da lógica?" (LISPECTOR, 1978, p. 13), pergunta a narradora de Água viva, para em seguida responder que quando se lida com a "matéria-prima", a lógica cartesiana cessa de ter importância. O que importa é "o que fica atrás do pensamento", "o inconcluso", o ser "orgânica", a "potência da potencialidade" (LISPECTOR, 1978, p. 13) - momento de desvendamento do ser das coisas. “Atrás do pensamento não há palavras: é-se. Nesse terreno do é-se sou puro êxtase cristalino. É-se. Sou-me. Tu te és" (LISPECTOR, 1978, p. 29). Seria o mesmo que dizer, nas palavras da autora portuguesa, que "o pensamento caminha para dentro de si, e esconde-se no ponto mais obscuro da palavra" (LLANSOL, 1985, p. 103)? Este o estado "muito novo e verdadeiro" que não permite classificação. Tensionar a palavra até os limites da linguagem, de modo que se exteriorize e abandone a si mesma no coração do desamparo é também tentar tocar o 
intocável, real impronunciável, e para isso há que se construir uma forma aberta e em continuidade, de maneira que se possa abrir caminho ao "novo, ao vivo, ao fulgor" (LLANSOL, p. 98, apud BRANCO, 2000:40).

Nesse sistema orgânico, o instante de leitura que não se faz sozinho é privilégio tanto de Llansol, quanto de Clarice. No primeiro parágrafo de Água viva, o leitor é interpelado pela narradora: "O próximo instante é feito por mim? ou se faz sozinho? Fazemo-lo juntos com a respiração" (LISPECTOR, 1978, p. 9). O texto é construído ao mesmo tempo pelo narrador e pelo leitor, mas não sem a presença quase que tutelar do corpo, repetindo assim o lugar do ler-escrever ritualizado em Um beijo dado mais tarde com a imagem do quadro de "Ana ensinando a ler a Myriam" como desígnio do livro. A busca central, que é também processo de aprendizagem, é a realização de uma leitura-escrita partilhada pelos participantes da cena literária, livres de qualquer posse. A textualidade, que se perfaz no momento da leitura e da escrita, revela a força de uma escrita em processo de formação, que se constitui a partir da convocação do corpo como agente de construção de um novo sujeito. Abandona-se o sujeito autocentrado e totalizante, despersonaliza-se o indivíduo até a nadificação completa de si para, logo em seguida, no centro da desorganização e do confronto, o homem, já liberto da "humanização" e já resguardado em essência, possa ressurgir em processo de reaprendizagem do ser, agora integrado a si mesmo, à alteridade e à physis. Dizer tal travessia é dizer também a viagem pelos limites de uma língua ainda com amarras, ainda presa a convenções e contornos definidos. A travessia consiste principalmente na desorganização de sistemas - linguístico, cultural, estético - para poder efetuar uma literatura que inicie quando se instaura o déficit do sistema. E para poder realizar a reconstrução de uma nova linguagem, na qual o abandono e a desorganização vividos pelo sujeito revelam-se como o trajeto de uma língua que se quer nova. Se a escrita denuncia, no caso de Clarice, a fratura do sujeito, e, no de Llansol, o apagamento do eu, ela também deixará à vista a rasura de si mesma. A queda sempre passa pela impressão no corpo, que da ruptura emerge fraturado, bem 
como a escrita que traz as marcas do corpo e se refaz rasura. Exemplos não faltam no corpus clariciano.

No conto "Preciosidade", o momento de despertar da personagem que, toda manhã, "vastamente abria os olhos" (LISPECTOR, 2008, p. 75), curiosamente acontecerá dentro do "devaneio agudo" em que vive, despertando para o real somente a partir "de um crime", na manhã "ainda mais fria e escura" (LISPECTOR, 2008, p. 75), zona indefinida e infernal da catábase clariciana. O crime, já prefigurado no início do conto, é retratado no momento epifânico da iniciação da personagem no mundo corpóreo do real. No conforto e segurança da sala de aula, a menina era "tratada como um rapaz" (LISPECTOR, 2008, p. 77) e “era inteligente", porém, ao sair pela manhã em direção à escola, havia o risco de ser notada como mulher pelos operários que viajavam no ônibus, pelos "homens que não eram mais rapazes" (LISPECTOR, 2008, p. 75). Havia o risco de se tornar ela mesma uma mulher, o que causava pavor e torpor. À menina inteligente correspondem os "riscos simétricos" que se saíssem "fora do círculo imaginário em que deveriam caber, tudo desabaria" (LISPECTOR, 2008, p. 75). A personagem era assim guiada pela "avidez do ideal". Na manhã do crime, acorda ainda dentro do "mesmo mistério intacto" apenas para caminhar agora rumo à descoberta do corpo e enxergar o real, arriscando-se a ser um "ela-mesma". Ver, portanto, torna-se a via crucis que permite a entrada no reino do invisível, no reino do ser "individual", do ser elamesma "que a tradição não amparava" (LISPECTOR, 2008, p. 81). O contato com o outro desconhecido e aterrorizante, que parece se apresentar apenas através do olhar, desenrola-se no contato físico do corpo, como que a revelar que aquele que vê o mistério também o toca e é tocado por ele. Após "o crime" e a paralisação inicial que a ele se segue, o primeiro movimento da personagem é de recuo até um muro, onde, corcunda, e, "como se tivesse um braço quebrado" (LISPECTOR, 2008, p. 82), encosta-se, deixando inscrita na parede a marca do corpo agora sem forma e rasurado. As orações que se seguem marcam a dupla revelação do mistério: "Ainda estava escuro. Depois amanheceu" (LISPECTOR, 2008, p. 83), como se amanhecessem o dia e a personagem. Como 
se a linguagem amanhecesse inaugural no teatro alquímico clariciano. A primeira imagem que vê em seguida é a de sua letra "redonda e graúda" (LISPECTOR, 2008, p. 83) inscrita no caderno e "que até essa manhã fora sua" (LISPECTOR, 2008, p. 83), já que após o contato com o mistério do desconhecido, o sujeito retorna fraturado e deformado. A letra escrita no caderno (diga-se no livro) é a mesma que o corpo inscrito na parede e revela a marca de uma escrita do corpo impressa no corpo da letra clariciana.

Tanto para Clarice quanto para Llansol, existir no mundo é existir com o outro, em uma sintaxe herdada do eu é o outro rimbaudiano, condutor da crise da modernidade vivida pelos sujeitos literários do século XX. Existir com o outro na palavra é participar do ato criativo junto a esse outro. O texto de ambas as autoras abre-se sempre para a construção do corp’áscrever junto ao corp’a'ler. Como aponta Silveira, "escrever e ler são uma troca de papéis" (SILVEIRA, 2004, p. 22), movimento através do qual surge a Poesia.

Este ser no mundo encenado pela experiência literária de Llansol e Lispector apresenta ainda dois outros sentidos. Nota-se que as obras de ambas as autoras estão sempre voltadas para a relação com a alteridade no limite da linguagem: o eu sujeito do mundo só existe enquanto tu objeto, desdobramento dos múltiplos eus existentes em cada ser e das relações possíveis entre os sujeitos. Afirma Llansol em Lisboaleipzig 2: “Há também relações, tensão e sentido que é onde esse meu tu existe. É disso que o mundo é feito, feito de vários mundos e de encontros de figuras" (LLANSOL, 2004, p. 23) e, poderíamos acrescentar, principalmente de encontros de figuras de um corp’áscrever da e na própria Poesia.

E assim como Llansol, Lispector preenche seus textos de personagens e cenas-fulgor que perpassam cada obra, que são um e o mesmo, mudando apenas de nome, moldando apenas um único e contínuo Livro, que se desenrola em outros, e que forma não apenas um livro, mas também um "destino". "Com um livro escreve-se outro livro" (LLANSOL, 2004, p. 23), porque um livro é vivo como um vegetal, e repete a metáfora já tão explorada do texto como tecido, como na narrativa do conto "Os desastres de Sofia", de Lispector, em 
que a história contada por Sofia permeia e adentra a história contada pelo professor em sala de aula, "ponto de desenlace” (LISPECTOR, 1975, p. 115) da história narrada pelo conto, e "começo de outras" (LISPECTOR, 1975, p. 115). A narrativa reveste-se na forma de fábula para repetir, em tom sustenido, o tema de todas as narrativas claricianas: a busca pelo eu, em viagem aos confins de si mesmo, desvelada pela escrita, que por sua vez também perfaz sua viagem em torno de si mesma, de uma tradição, de uma cultura, de uma História. E, afinando com a técnica do myse-en-abîme que lhe é tão cara, diz a narradora: “Meu enleio vem de que um tapete é feito de tantos fios que não posso me resignar a seguir um fio só; meu enredamento vem de que uma história é feita de muitas histórias" (LISPECTOR, 1975, p. 98).

Se a narrativa clariciana é uma e a mesma história contada de diferentes maneiras, poderíamos dizer que, de seu lado, a narrativa llansoliana também percorre o mesmo caminho. Se o Livro é um canto de narrativas, enlace de muitos fragmentos em um só "contínuo" e "enfeitiçado" grande canto de "ave de fogo", esses fragmentos ficcionais também se misturam aos fragmentos de vida formando um todo. A narradora de Um beijo dado mais tarde afirma: "Anna Magdalena, se ela contasse como eu, cantaria sempre; tem um canto de narrativa que é uma acumulação de pequenas histórias e todas elas correm umas sobre as outras, a rir e a voar" (LLANSOL, 1990, p. 45). Entretanto, a mesma narradora ensina que o principal não é o enredo em si que acompanha a história, porque este já é conhecido pelo "leitor bem treinado". O que "interessa à escrita" é o "momento de desvendamento" (LLANSOL, 1990, p. 45) que numa história há ou não há, porque “Esse momento, tornado longa sequência sustentadora da vibração explícita, é o nome da escrita" (LLANSOL, 1990, p. 45); esta é a "face escondida das técnicas narrativas já tradicionais" (LLANSOL, 1990, p. 45) que interessa desvendar. Para chegar a essa verdade desvelada, a narradora de Causa amante confessa a sua ars poetica: é necessário ligar-se a uma ideia "e examiná-la cuidadosamente" (LLANSOL, 1990, p. 48) porque "quando um pensamento é verdadeiro podem deduzir-se, sem interrupção, outros 
pensamentos verdadeiros" (LLANSOL, 1990, p. 48) que se encontram inesperadamente no diverso e formam uma ficção.

Uma poética atrás do pensamento é também uma poética que se liga a uma ideia, sem se desligar do sensível, da experiência vivida pelo corpo. "As coisas são veículo de conhecimento, à medida que se dispõem, experimentam o nosso pensamento e submetem à prova a nossa maneira de agir" (LLANSOL, 1987, p. 89) porque não se trata de falar "nem do abandono da vida, nem do abandono da razão" (LLANSOL, 1990, p. 45), mas da união dos opostos, unidos em um só desígnio: um corp'a'screver. E, como imagem que se impõe enquanto desígnio do livro, é na descrição da estátua da mulher ensinando a outra a ler que se apresenta o princípio de complementaridade do texto llansoliano: “Ana ensinando a ler a Myriam é uma idéia. A bela idéia de uma imagem perene" (LLANSOL, 1990, p. 45).

Assim, as obras de Clarice Lispector e Maria Gabriela Llansol podem ser lidas pela ótica de uma poética da imagem, na qual o olhar se torna o guia principal dentro da noite escura infernal rumo à descoberta do corpo e da linguagem no corpo do texto, até a coroação do ser verdadeiro reintegrado ao real e a si mesmo.

A narrativa respira, segue o ritmo sistólico e diastólico da "veia que pulsa”, oculta, atrás do pensamento. "O mundo não tem a ordem visível e eu só tenho a ordem da respiração. Deixo-me acontecer" (LISPECTOR, 1978, p. 24), afirma a narradora de Água viva, conduzindo o olhar do leitor, que estanca surpreendido diante de uma escrita do corpo, exigindo-lhe o mesmo grau de comprometimento. A música, bem como a literatura e a pintura, precisa da instância corporal para tornar-se acontecimento, já que para gravar o incorpóreo, necessita-se compreender e experimentar o corpóreo. Diz a narradora de Água viva: "É também com o corpo todo que pinto os meus quadros e na tela fixo o incorpóreo, eu corpo-a-corpo comigo mesma. Não se compreende música: ouve-se. Ouve-me então com teu corpo inteiro" (LISPECTOR, 1978, p. 10). Falar da contração e da distensão é falar também de silêncio e palavra, pausa e movimento - morte e nascimento - ritmo incessante 
da vida contínua. Logo, o tema clariciano por excelência é o deslocamento, que põe em circulação descontinuidades temporais, espaciais, imagéticas e linguísticas, de modo a desenvolver uma escrita que solidifica os laços do diálogo semiótico entre pintura e música. “Fixo instantes súbitos que trazem em si a própria morte e outros nascem - fixo os instantes de metamorfose e é de terrível beleza a sua seqüência e concomitância" (LISPECTOR, 1978, p. 13). A narradora declara nesse parágrafo a sua arte poética.

O mesmo compromisso com o corpo ocorre na narrativa llansoliana. Se o momento fixado pelo texto clariciano é o da morte e nascimento concomitantemente (e as cenas de nascimento são numerosas), para Llansol a metamorfose do ser encontra sinônimo na mutação. A mutação é o primeiro dos três movimentos na narrativa llansoliana que provocam medo e tremor ao personagem-narrador. Transformar-se é morrer para renascer, é tocar os limites desconhecidos do homem, é retirar a máscara da "humanização" para encontrar o novo homem, a forma de criança-semente em brotação. A segunda é o vazio provocado pela despersonalização. Transformar-se é também sentir na matéria movente o processo de metamorfose. O terceiro movimento a se temer é um corp'áscrever, isto é, a experiência da escrita com o corpo, a experiência do pensamento que passa pela vivência do corpo e que libera a energia geradora de uma potência de agir. Em Um beijo dado mais tarde, o que Témia fazia durante o dia era inventar a lógica do ato de escrever como ato de amar. E aqui a chave de leitura que a narradora descobre e oferece ao leitor é o sexo de ler. "Do sexo para a melodia da palavra há um caminho" (LLANSOL, 1990, p. 57), caminho este que devolve vida e força à letra. O mesmo deseja o texto clariciano: “E se tenho aqui que usar-te palavras, elas têm que fazer um sentido quase que só corpóreo" (LISPECTOR, 1978, p. 11). O texto torna-se o lugar da relação com o vivo, com o ser em sua extensão e comunhão máxima. Tal comunhão exige entrega total, tanto de quem escreve como de quem lê, a ponto de o ato de escrita/leitura tornar-se ato de amar. Como aponta João Barrento:

O que nesse Texto-(do)-Vivo põe em ação os afetos, de forma diversa da das convenções da narrativa, é essa força da libido 
que informa, tanto a imaginação criadora como o corpo de quem escreve (e dá ao texto o seu 'sexo') e de quem lê (com o 'sexo' de ler que esse texto lhe pede). É isto que explica a exigência, para o texto llansoliano, não de simples leitores, mas de legentes, leitores que 'lêem em amor' (BARRENTO, 2001, p. 141).

No primeiro parágrafo de Água viva, onde se tematizará o movimento autoformativo da escrita, nota-se a preocupação com uma letra viva, que busca não apenas a desorganização das fronteiras que provocam a dissociação das linguagens expressivas, inclusive aquela entre os seus participantes - aquele que escreve e aquele que lê - mas precisamente o ponto de indiscernibilidade entre tais linguagens. Para além de sons, signos ou imagens, Clarice instaura uma nova expressão literária que envolve inclusive o silêncio, ponto de encontro onde todas as expressões se fundem para exprimir o inexprimível, o impronunciável, o desconhecido: o núcleo vivo da vida. Na própria epígrafe de Água viva está contido o sentido da escrita clariciana:

\footnotetext{
"Tinha que existir uma pintura totalmente livre da dependência da figura - o objeto - que, como a música, não ilustra coisa alguma, não conta uma história e não lança um mito. Tal pintura contenta-se em evocar os reinos incomunicáveis do espírito, onde o sonho se torna pensamento, onde o traço se torna existência" ii
}

Uma pintura livre da dependência da figura é o abstrato? Uma pintura, bem como a música, que não ilustre, conte história ou lance mito, mas na qual sonho é o mesmo que pensamento, e traço o mesmo que existência, é uma pintura cujo significado maior é o da experiência em si. Trata-se da captura do movimento contido na experiência. As tentativas da narradora de Água viva de capturar o instante-já, o segundo e todos os seus segmentos, consistem em experimentar o instante que cabe em qualquer tempo, o Agora de que fala Bergson, que não está contido em nenhuma medida temporal ou espacial definidas, é apenas vivido, isto é, tem a dimensão da experiência. O mesmo acontece em Um beijo dado mais tarde quando a dimensão temporal da narrativa, 
bem como suas vozes, se confunde em sobreposição de nascimentos, falas e línguas. Há, pelo menos, dois planos de escrita: uma alternância entre a sua anunciação - plano no qual a narradora é narradora - e a anunciação do enunciado, no qual a narradora é personagem. Da mesma forma, há dois planos nos quais o leitor é apenas leitor: um, a ler passivamente a forma formada da enunciação, e outro no qual o leitor se torna legente, criando junto à narradora o próprio texto.

Mas como dar a ver o mistério que é intocável, o verbo que não se pronuncia? Partindo da técnica pictórica usada por Clarice em seus textos, Carlos Mendes de Sousa (SOUSA, 2000, p. 290) concentra sua análise na relação imagem/texto que se faz presente in absentia, ou seja, a imagem que é apenas evocada no texto. Como podem ser "evocadas" sem serem "nomeadas"? A "possível linguagem" não é a da palavra, mas a da mudez. Nomear é também designar, isto é, tornar real o indizível por meio da linguagem. No entanto, diz a narradora de A Paixão Segundo G.H.: "A linguagem é um esforço humano" e o indizível "só poderá ser dado através do fracasso da linguagem" (LISPECTOR, 1979, p. 171). A resposta à pergunta anterior só pode ser: a imagem é evocada pelas referências pictóricas que envolvem o quadro, a tela, o pintor, a paisagem, etc., ou por meio de um impressionismo literário, iniciado pela autora brasileira através do novo sistema de signos que inventa para dar origem à sua linguagem pessoal. "Para me interpretar e formular-me preciso de novos sinais e articulações novas em formas que se localizem aquém e além de minha história humana. Transfiguro a realidade e então outra realidade sonhadora e sonâmbula me cria" (LISPECTOR, 1978, p. 22).

Portanto, é preciso reinventar uma nova forma de escrever e de dar significado à realidade. Clarice Lispector vai buscar nas outras artes uma maneira de explicar o funcionamento da sua escrita. Assim, segundo Carlos Mendes de Sousa, o gesto é onde "melhor se traduz a figuração" (SOUSA, 2000, p. 294), pois o gesto é visual e sugestivo. O gesto clariciano (e, arriscamos dizer, também o llansoliano) alterna-se ora em gesto de escrita, ora de pintura, exatamente como sugestão para a narração do indizível. Como fabricar cores 
com as palavras? Como reinventar a tinta? Como envolver o corpo na escrita? A resposta é: tornando as palavras úmidas e secas como a tinta por meio do som e da imagem que evocam. "Quero como poder pegar com a mão a palavra. A palavra é objeto? E aos instantes eu lhes tiro o sumo da fruta. Tenho que me destituir para alcançar cerne e semente de vida. O instante é semente viva" (LISPECTOR, 1978, p. 12).

Se a narradora de Água viva eleva a palavra ao sentido corpóreo ("enviar uma seta no ponto nevrálgico e tenro"), se dá corpo à palavra, quer dizer que esta é coisa viva, com acentuado caráter físico. E se a palavra forma o corpo do texto ou o texto do corpo, então esse texto é "água viva”, é ser vivoiii. Torna-se importante a seta que atinge o alvo, o caminho percorrido pela flecha que dará rumo à sequência de imagens, chave de leitura do universo clariciano. A narradora oferece o percurso sinestésico que convoca, na leitura, o ato de olhar: "O que te digo deve ser lido rapidamente como quando se olha" (LISPECTOR, 1978, p. 17). A escrita é para a pintura como o esboço (desenho - estrutura) que antecede a tinta: "Escrevo-te como exercício de esboços antes de pintar" (LISPECTOR, 1978, p. 18). O desenho apresenta-se como uma forma de escrita e vice-versa. $\mathrm{O}$ ato da escrita antecede o da pintura e, como pintar conflui depois para a fotografia, pois se entende o texto como arquitetura do imaginário, ao dizer "vejo palavras" e não 'leio palavras' está a narradora a equivaler o texto a uma grande tela na qual se pode observar o todo com suas partes. Assim, o texto exige o uso da visão como quando se observa uma pintura. Portanto, o que se vê é um quadro, tanto quanto o que se lê é um poema.

O mesmo acontece com o texto de Llansol: em Um beijo dado mais tarde, a narradora diz que no seu trabalho de escrita fixa intensamente "um pontopaisagem antes de começar a escrever" para, em seguida, voltar o olhar para si mesmo, de modo que se ouçam "as ondulações vibratórias desses dois pontos" (LLANSOL, 1985, p. 112), de modo que se constitua uma aprendizagem por meio do saber intuitivo que leva a "ver oralmente" (BARRENTO, 2005, p. 143). Os olhos recebem então "num ponto-voraz" as imagens, também chamadas de figuras, que revelarão o silêncio do indizível. 
Walter Benjamin via no olhar um poder da memória, que se apresenta como memória involuntária. Esta oferece um conjunto de imagens que forma a aura de um objeto e se agrupa em torno dele. O objeto aurático relaciona-se com o desdobramento de imagens do objeto, para além da visibilidade, portanto, tão importante quanto o que é visível são as imagens que também não são vistas, que funcionam como canal de abertura e poetização, trabalho de muitas outras significações que revelarão as obras do inconsciente. Todos os tempos são trançados e redimensionados dentro dessa memória. E, segundo DidiHuberman, na releitura da obra de Walter Benjamin, a partir desse poder da memória o paradigma do sonho aparece, uma vez que no inconsciente escondem-se as latências; como se dentro do espaço da memória, onde a ideia de tempo é desfeita e refeita, houvesse inclusive o redimensionamento das relações, no qual o que vê tem a mesma posição e peso daquilo que é visto. Portanto, no espaço da latência existe a correspondência entre o que olha e o que é olhado; é neste espaço que os símbolos ganham vida e olham os homens, assim como os homens os olham. Huberman assinala a importância que o "tesouro do simbólico" assume, pela complexidade e trama de seus significados, pela confluência de caminhos a que o símbolo guia nossos olhos, e que é esta posição de relevância que faz com que a trama "apareça", surja, irrompa "como um acontecimento visual único" (DIDI-HUBERMAN, 1998, p. 150) a desestabilizar a organização interna do olhar por tornar próximo algo que antes não se enxergava e não se conhecia, na forma de uma posse, como se subitamente pudéssemos tocar, agarrar, prender esse invisível que se materializa diante de nossos olhos.

Nesse sentido, a narradora de Água viva manifesta aquilo que pode ser entendido como o código de escrita clariciano, que servirá também para entender o código llansoliano, e que se reverte em "tela antes virgem, agora coberta de cores maduras", pintada "há algum tempo e em outro domingo" (LISPECTOR, 1978, p. 18). O sujeito, em sua nova fase de pós-liminaridade, fase "sem fronteiras", espaço da total reconciliação, "se apodera dos desvãos" de si mesmo, preenche os espaços vazios, antes interditados pela separação e 
prepara-se para a fecundação, cujo fruto originário é: o texto. Instala-se o código - "meio concreto de falar" - através do qual se possa dar conta do "fluxo" do tempo, que repete o da vida. Este código, presente nas escritas das duas autoras, revela o "atrás do atrás do pensamento", aquilo que compõe o ser, mas que não é visível ou racionalizado. Inconsciente? Intuição? Poesia?

\section{Referências bibliográficas:}

BARRENTO, João. O livro torna o sexo invisível. In: Metamorfose, Editorial Caminho e Cátedra Jorge de Sena/UFRJ, v. 4, p. 135-144, set, 2003.

A origem de ler. Sobre Um beijo dado mais tarde. Lisboa: Roma Editora, 2005.

BRANCO, Lucia Castello. Os absolutamente sós - Llansol - a letra - Lacan. Belo Horizonte: Autêntica; FALE/UFMG, 2000.

DIDI-HUBERMAN, Georges. O que vemos, o que nos olha. São Paulo: Ed. 34, 1998. MEXIA, Pedro. Um texto como um tecido. In: Diário de Notícias. Lisboa, ago 2005.

LISPECTOR, Clarice. Água viva. 2. ed. Rio de Janeiro: Nova Fronteira, 1978. "Os desastres de Sofia". In: Felicidade Clandestina. 3. ed. Rio de Janeiro: Nova Fronteira, 1975.

A paixão segundo G.H. 6. ed. Rio de Janeiro: Nova Fronteira, 1979.

"Preciosidade". In: Laços de Família. Lisboa: Cotovia, 2008.

LLANSOL, Maria Grabriela. Um falcão no punho - Diário 1. 1. ed. Lisboa: Rolim, 1985.

Um beijo dado mais tarde. 2. ed. Lisboa: Rolim, 1990.

Lisboaleipzig 2 - O ensaio de música. Lisboa: Rolim, 1994.

Finita - Diário 2. 1. ed. Lisboa: Rolim, 1987.

SILVEIRA, J. Fernandes da. O beijo partido: leitura de Um beijo dado mais tarde: introdução à obra de Llansol. 1. ed. Rio de Janeiro: Bruxedo, 2004.

SOUSA, Carlos Mendes de. Clarice Lispector. Figuras da Escrita. 1. ed. Braga, 
Universidade do Minho/Centro de Estudos Humanísticos, 2000.

\begin{abstract}
${ }^{\mathrm{i}}$ Mexia, Diário de Notícias, 2005.
ii Trecho de Michel Seuphor utilizado por Clarice como epígrafe de Água viva.

iii Vale lembrar que Clarice se sabe pertencente a uma tradição literária ocidental, fato que nos permite ouvir os ecos dessa tradição em sua escrita. Lembremos, portanto, da magia e do poder sugestionador que a lírica de Mallarmé exerce sobre o leitor de maneira a despertar a multiplicidade de leituras e sentidos que a poética permite e exercita. O leitor torna-se um continuador do ato produtivo, revelando que a tarefa oculta da poesia é escapar à conclusão finita. Com isso, Mallarmé inventa uma linguagem que impele o leitor a uma com-participação (para falar próximo a Schlegel) enquanto potência interpretativa infinita rumo à intuição do enigma poético. Assim, pode-se falar do livro inconcluso, construído junto ao leitor, e que se quer infinitamente inacabado.
\end{abstract}

